\title{
Census based deprivation indices: their weighting and validation
}

\author{
David Gordon
}

\begin{abstract}
Key issues - Over one hundred years of social science research has shown that different social groups have different probabilities of suffering from multiple deprivation; yet census based deprivation indices frequently assign equal weightings to each of their component variables. This becomes highly problematic when these indices are used as the basis for allocating resources to local and health authorities. In order to ensure fairness and accuracy in resource allocation these indices should be both weighted and validated.

Study results - Weightings are derived from the Breadline Britain in the 1990s survey to produce a census based deprivation index that estimates the percentage of poor households at electoral ward level. Examples of validation methodology are discussed and the estimate of the proportion of poor households is shown to be highly correlated with both low income and morbidity as estimated from the 1991 census.

Data sources - The 1991 census local base statistics (LBS) and small area statistics (SAS) aggregated for the 8519 electoral wards of England. The Breadline Britain in the 1990s survey: a nationally representative survey of 1831 households specifically designed to measure poverty and multiple deprivation.
\end{abstract}

( $(\mathcal{F}$ Epidemiol Comm Health 1995;49(Suppl 2):S39-S44)

The construction of census based deprivation indices is one of the most economically important uses of social statistics since they form a key element in the allocation of both local government and health resources. However, none of the questions in the 1991 census was specifically designed to measure either poverty or deprivation and any census based index must comprise variables that are, at best, proxy indicators of deprivation rather than direct measures. It is not surprising therefore that a bewildering array of indices has been proposed, using different combinations of variables and different statistical methods.

The key question is, "Which index is the best?" This question can be divided into two parts: firstly, what does the index measure (if anything) and, secondly, which index provides the most accurate and precise measurement? Answering these questions is often a far from a simple matter. Advocates of new census based deprivation indices rarely make detailed com- parisons between their index and others. Similarly, theoretical discussions on the nature and measurement of deprivation are often dealt with in a cursory manner or are entirely lacking from many papers. Indeed, many deprivation indices seem to be composed of combinations of variables that the authors think measure something "bad". Although, what this "bad" thing is is often unclear. Various statistical procedures and transformations are often performed on the indices components, usually in order to ensure equal weighting - that is so that each variable provides an equal contribution to the final index. The justification for such statistical procedures, however, is often absent. The terms "deprivation" and "multiple deprivation" are generally used loosely, with little reference to their specific technical meanings.

Under these circumstances, it is not surprising that the non-specialist (and often the specialist) has difficulty in selecting a deprivation index. Despite these problems, it is relatively easy to describe the broad pattern of the distribution of poverty within a region. Figure 1 shows the estimated percentage of poor households (for the definition of poor households see below) in the 366 local authority districts of England. ${ }^{1}$ The districts have been divided into approximate quartiles (the poorest $25 \%$ of authorities, the next $25 \%$ and so forth), and a clear pattern is evident on the map. There are high numbers of poor households living in inner London, Tyneside, Merseyside, Greater Manchester, and into Yorkshire. Poor households are also found in the major cities and in rural districts of Cornwall, East Anglia, Kent, Cumbria, and Northumberland.

The same pattern is evident from maps produced using the social deprivation (SOCDEP) index of Forrest and Gordon, ${ }^{2}$ the "Townsend index" $Z$ score $^{3}$ (the most widely used deprivation index) and the Department of Environment's index of local conditions ${ }^{4}$ (the current "official" deprivation index). Since these indices use different combinations of variables and different statistical methods, these striking similarities are remarkable and indicate that by 1991, poverty had become so widespread in England and its manifestations were so varied, that the same broad patterns can be discerned almost irrespective of the methods used to measure it. To put it bluntly, when there is a lot of poverty, it becomes relatively easy to measure. ${ }^{1}$

Although there are broad similarities between the results obtained from these different indices, there are considerable differences in the specific rankings. This is important if these indices are to be used to allocate resources. 


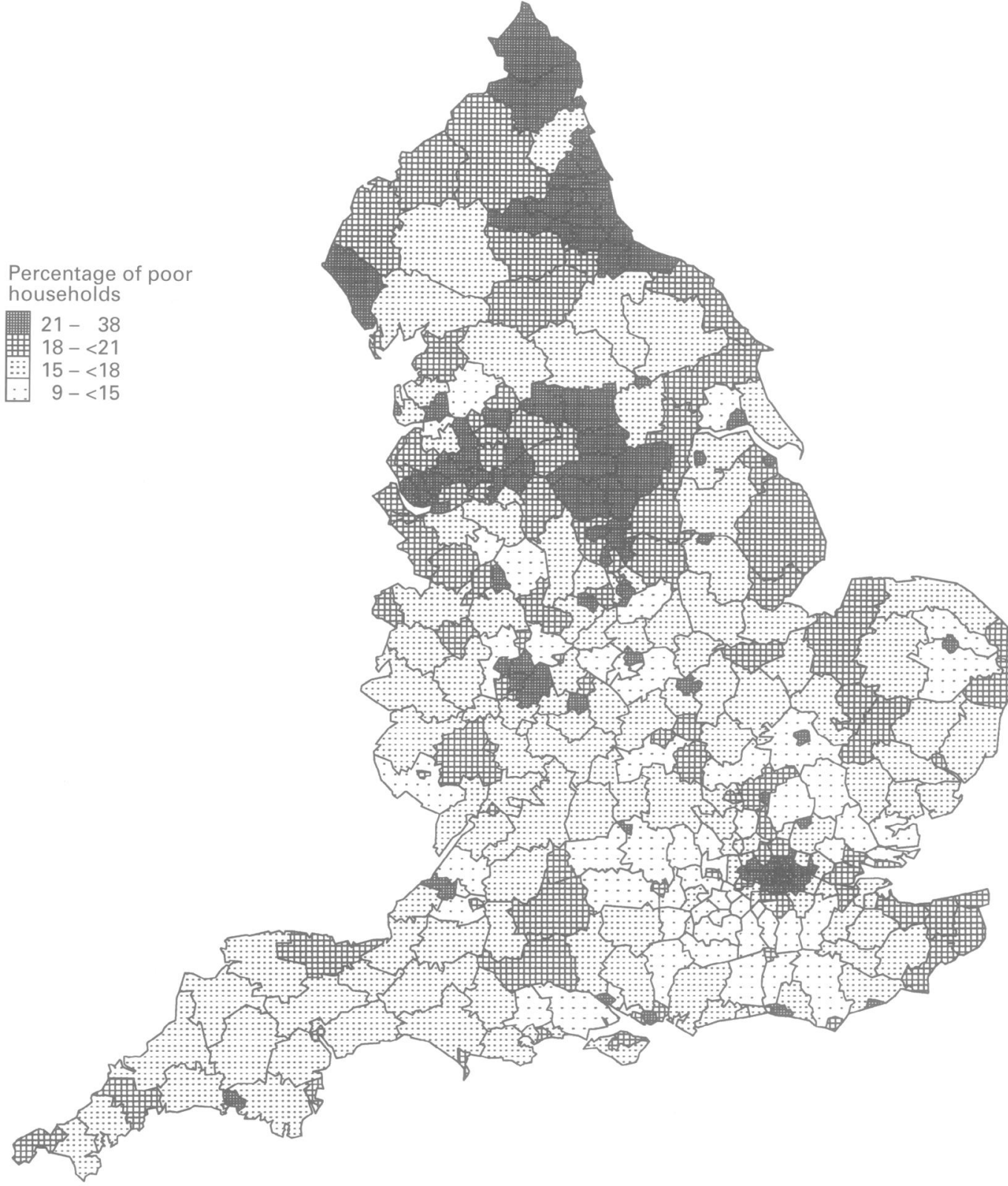

Figure 1 Percentage of poor households in local authority districts of England.

These differences become even more marked when smaller and more homogeneous geographical areas (such as electoral wards) are compared.

The theory of poverty and deprivation To measure deprivation/poverty more accurately, it is necessary to be precise about the meaning of these terms. There are two basic concepts in social science: the "absolute" and "relative" theories. The "absolute" concept of poverty is dominated by the individual's requirements for physiological efficiency. However, this is a very limited view of human needs, especially when considering the roles that men and women play in society. People are not just physical beings, they are social beings. They have obligations as workers, parents, neighbours, friends, and citizens that they are expected to meet and which they themselves want to meet. Studies of people's behaviour after they have experienced a drastic cut in resources show that they sometimes act to fulfil their social obligations before they act to satisfy their physical wants. They require income to fulfil their various roles and participate in the social customs and associations to which they have become habituated and not only to satisfy their physical wants. ${ }^{5}$

Poverty can be defined as the situation in which resources are so seriously below those commanded by the average individual or family that the poor are, in effect, excluded from ordinary living patterns, customs, and activities. As resources for any individual or family are diminished, there is a point at which there occurs a sudden withdrawal from participation in the customs and activities sanctioned by the culture. The point at which withdrawal escalates disproportionately to falling resources can be defined as the poverty line or threshold. ${ }^{67}$

This "relative" concept of poverty is now widely accepted. ${ }^{8}$ It is not easy, however, to measure poverty directly, ${ }^{9-11}$ but it is possible 
to obtain measures of "deprivation". These two concepts are tightly linked and there is general agreement that the concept of deprivation covers the various conditions, independent of income, experienced by people who are poor, while the concept of poverty refers to the lack of income and other resources which makes those conditions inescapable or at least highly likely. $^{12}$

\section{The measurement of poverty and deprivation}

From these definitions, it is clear that to measure poverty/deprivation accurately, surveys or censuses must be used that establish both the "normal" or "average" standard of living of the majority in a society/culture and any "enforced" reductions in this standard dut to lack of resources.

Social scientists have been using deprivation surveys to study poverty in Britain for over a hundred years. All these surveys have shown that some groups are more likely to suffer from multiple deprivation than others (that is, lone parents and the unemployed are not equally likely to be living in poverty and indices that consider them to be so are probably wrong.) Therefore, census based deprivation indices that give equal weight to their component variables are likely to yield inaccurate results.

Since all census based deprivation indices are generally composed of surrogate or proxy measures of deprivation rather than direct measures, there are two basic requirements they should fulfil to ensure accuracy:

- The components of the index should be weighted to reflect the different probability that each group has of suffering from deprivation; and

- The components of the index must be additive - for example, if an index is composed of two variables, unemployment and lone parenthood, then researchers must be confident that unemployed lone parents are likely to be poorer than either lone parents in employment or unemployed people who are not lone parents.

Weighted indices also have the advantage that their results are often much easier to understand, for example, that in Brent $25 \%$ of households are living in poverty has a much greater intuitive meaning than saying that Brent has a Townsend Z-score of $7 \cdot 86$ or a Department of Environment index of local conditions signed $\chi^{2}$ score of $22 \cdot 46$.

Logistic regression results

\begin{tabular}{llll}
\hline & Relative weights & Odds ratio & $95 \%$ Confidence Interval \\
\hline Unemployment & $0 \cdot 094$ & $1 \cdot 7$ & $2 \cdot 5,1 \cdot 1$ \\
Long term illness & $0 \cdot 108$ & $1 \cdot 9$ & $2 \cdot 5,1.1$ \\
Social class IV \& V & $0 \cdot 159$ & $2 \cdot 5$ & $3 \cdot 4,1.9$ \\
No car & $0 \cdot 217$ & $3 \cdot 6$ & $4 \cdot 8,2.7$ \\
Not owner occupied & $0 \cdot 203$ & $3 \cdot 3$ & $4 \cdot 3,2.4$ \\
Lone parents & $0 \cdot 160$ & $2 \cdot 5$ & $4 \cdot 6,1 \cdot 4$ \\
\hline
\end{tabular}

Relative weights have been calculated from the $\beta$ coefficient.

\section{Obtaining weightings for census based} deprivation indices

The easiest method of obtaining weightings for component variables in census based deprivation indices is to use a survey (conducted at or around the same time as the census) that was specifically designed to measure poverty and deprivation. The weightings used to estimate the percentage of poor households, shown in figure 1, were derived from the Breadline Britain in the 1990 s survey ${ }^{1315}$ - a nationally representative survey designed specifically to measure the extent and nature of poverty in Britain at the end of 1990 (that is, a few months before the census). (For the Breadline Britain in the 1990s survey, MORI interviewed a quota sample of 1319 adults aged $16+$, face-to-face in their homes, between 14 and 25 July 1990. Additional fieldwork among households living in particularly deprived areas was carried out between 26 November and 9 December 1990, with 512 quota interviews conducted face to face in home. Quotas were based on sex, age and working status. Aggregated data were weighted by age, household type, tenure and ACORN housing type to be representative of the population of Great Britain.) ${ }^{13}$ The previous breadline Britain survey, in 1983, had pioneered the "consensual" or "perceived deprivation" approach to measuring poverty, which is defined from the viewpoint of the public's perception of minimum need:

"This study tackles the questions 'how poor is too poor?' by identifying the minimum acceptable way of life in Britain in the 1980s. Those who have no choice but to fall below this minimum level can be said to be 'in poverty'. This concept is developed in terms of those who have an enforced lack of socially perceived necessities. This means that the 'necessities' of life are identified by public opinion and not by, on the one hand, the views of experts or, on the other hand, the norms of behaviour per se. "16

The 1990 survey asked respondents about a list of 44 items designed to cover the range of possessions and activities that people might consider important. Respondents (and their households) were assigned a deprivation index score each time they answered that they "don't have and can't afford" an item that was considered to be a necessity by more than $50 \%$ of respondents (32 out of the 44 items were considered to be necessities by more than $50 \%$ of respondents after the sample had been weighted to represent the population.) The resulting 32 item deprivation index has been shown to be highly reliable (Cronbach's Alpha $0 \cdot 8754$ ) and effectively identical results would have been obtained if different sets of questions on deprivation had been asked. ${ }^{15}$

The "poverty line" was identified at a deprivation index score of 3 (that is, people/households lacking three or more socially perceived necessities) using the discriminant analysis methodology of Townsend and Gordon. ${ }^{1517}$ The existence of a clear poverty "threshold" has been independently confirmed, using a different methodology by Hallerod, Bradshaw and Holmes. ${ }^{18}$ Weightings were obtained using logistic regression for the best subset of dep- 
rivation indicator variables that were measured in both the 1991 census and the breadline Britain survey.

Eleven variables, which have been used in one or more census based indices, were examined:

- Unemployment

- Lone parents

- Limiting long term illness/disability

- Unskilled/low social class

- No access to a car

- Living in rented accommodation (not owner occupied)

- Single pensioners

- Divorced people

- Widows

- Lacking or sharing basic amenities (indoor toilet, bath/shower)

- Not self contained accommodation

There was a considerable degree of overlap between single pensioners and widows and both variables were excluded because they were not good predictors of poverty. Divorced people were excluded because of their high overlap with single parenthood, which was a better predictor of poverty. "Lacking basic amenities" and "not self contained accommodation" were dropped because they were found not to be additive ${ }^{6}$ eg households which contained someone with a limiting long term illness and also lacked basic amenities were not likely to be poorer than a household with an ill person but with basic amenities. The reason for this is that many poor disabled people live in local authority accommodation which invariably have indoor toilets and bathrooms. Standard statistical techniques were used to establish additivity. First order interaction plots were produced using the Minitab $\mathrm{v} 10 \cdot 2$ package and fully saturated ANOVA and GLM models were used to examine higher order interactions.

The relative weightings and the odds ratios from the logistic regression results are shown

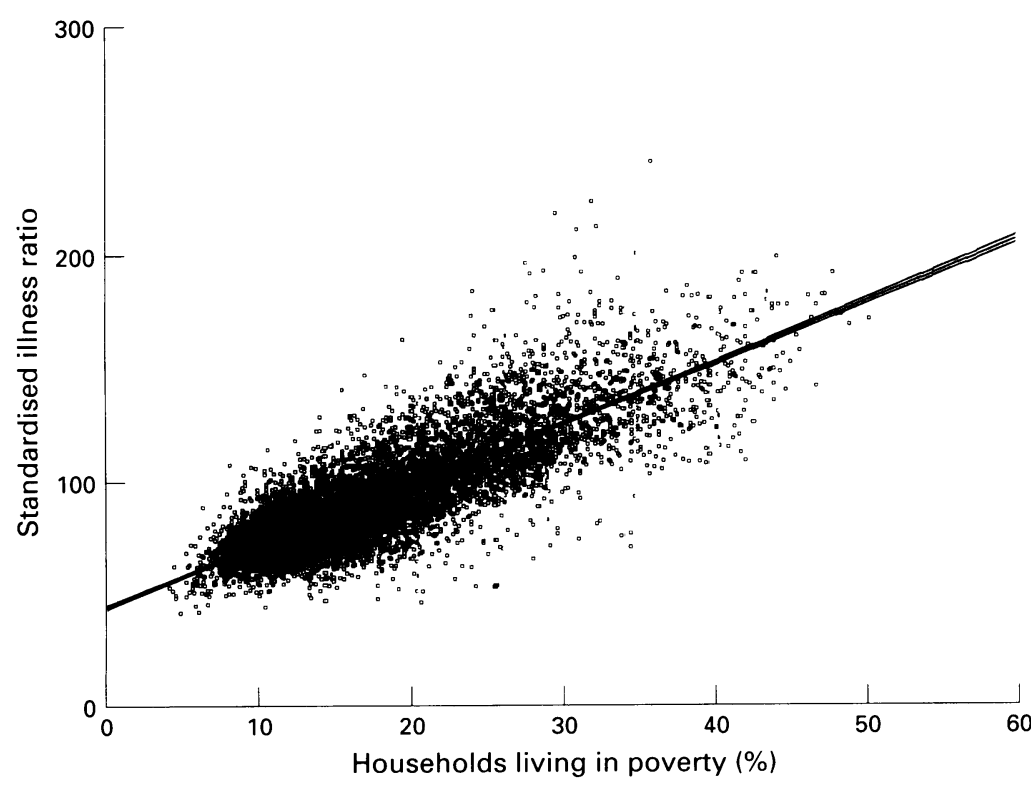

Figure 2 Estimated percentage of poor households in relation to the standardised illness rates for the 8519 electoral wards of England. in the table. The regression equation classifies $82 \%$ of the cases correctly, which means that even using the best weighted subset of variables available from the census, there is still a one in five error rate. Basically, the census is not designed to measure poverty and therefore does not do it particularly well. However, an estimate of the number of poor households in an area can be calculated as: $21 \cdot 7 \%$ of the number of households with no access to a car $+20.3 \%$ of the number of households not in owner occupied accommodation $+16 \%$ of the number of lone parent households $+15.9 \%$ of the number of workers in social classes IV and V $+10.8 \%$ of the number of households containing a person with a limiting long term illness $+9 \cdot 4 \%$ of unemployed workers.

Poverty, low income, and state benefits Recently, Davies et $a l^{19}$ used the family expenditure survey (FES) and general household survey (GHS) to produce a set of weightings that can be used with census variables to predict the number of low income households (the bottom quintile): and Noble et al ${ }^{20}$ have suggested weightings to predict households in receipt of state benefits (income support) Although there is a considerable overlap between poor households, low income households, and households on benefit, these groups are not identical. Specifically, pensioners, lone parents, and the self employed often have low incomes (as measured in the FES and GHS) but have a reasonable standard of living due to previously accumulated wealth. Similarly, people who have only recently got a job after a period of unemployment, may have reasonable incomes but a low standard of living. These factors mean that there is only a $55-75 \%$ overlap between low income households and poor households. ${ }^{1521}$

The correspondence between low income households and households in receipt of state benefits is of a similar magnitude. The DSS households below average income statistics ${ }^{22}$ show that, in $1991 / 92$, only $59 \%$ of households in the bottom decile of income received any state benefits (including pensions). Similarly, the last set of low income statistics, produced for $1992^{23}$ showed that, of the 13680000 people in families with incomes at or below the income support level, only $65 \%$ were receiving income support. The breadline Britain in the 1990 s survey found that only $56 \%$ of nonpensioner households, in receipt of income support, were also living in poverty.

\section{Validation of census based deprivation indices}

To test the accuracy of a census based deprivation index, it is advisable to use one or more validation procedures. Since the publication of The Black report, ${ }^{24}$ literally hundreds of studies have been published demonstrating that, after age and gender, poverty is one of the major determinants of ill health. Similarly, all things being equal, poor households are likely to have less income than non-poor households. There- 
fore, ill health and income can be used as validation criteria for deprivation indices.

Figure 2 shows a scatter plot of the estimated percentage of poor households against the standardised illness ratio (SIR) for the 8519 electoral wards of England. The regression line with a $95 \%$ confidence interval is also shown. There seems to be very good agreement between these two variables (Pearson's product moment correlation $0 \cdot 82$ ). The SIRs were calculated at the individual level, from the results of the limiting long term illness question in the 1991 census, using the indirect standardisation methodology of Forrest and Gordon. ${ }^{2}$ The prevalence rates of limiting long term illness in the 1991 census for people under 75 have been shown to be very similar to the prevalence rates of disability as "objectively" measured in $1985-88$ by the OPCS disability surveys. ${ }^{2}$ Response bias for the limiting long term illness question is not thought to vary by geographical area. $^{26}$

Although the 1991 census collected no information on income, detailed information on occupation is available. Table 99 of the local base statistics lists occupation grouped into 77 categories by gender. It is possible to estimate the average income from earnings for an area by multiplying the number of men and women in each occupational group by the average weekly full time earnings of that occupation as recorded in the 1991 new earnings survey. Adjustments are then made for the numbers in part time work, those on government schemes, and the unemployed. Finally, this total figure is divided by the economically active population to give an average estimated income from earnings.

This methodology does not give accurate absolute figures for income since no estimate is made of unearned income (for example dividends from stocks and shares, etc). However, since people of working age with the highest earned income tend also to have

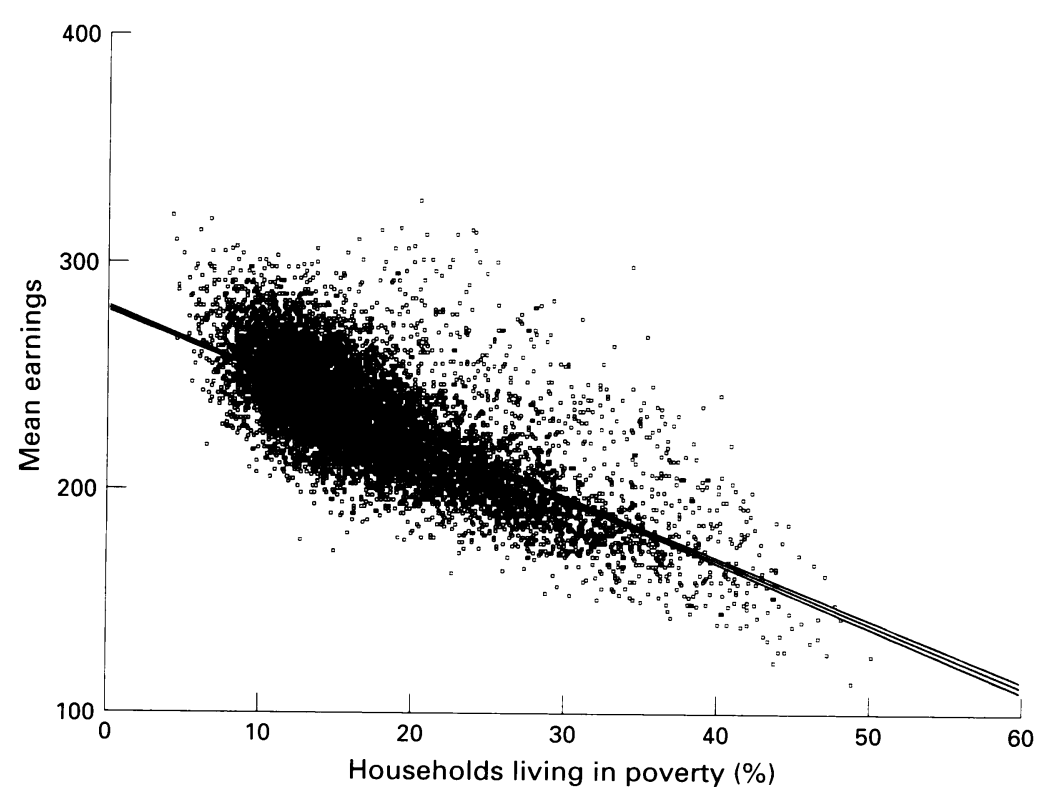

Figure 3 Estimated percentage of poor households in relation to estimated average earnings for the 8519 electoral wards of England. higher unearned income, ${ }^{27}$ the variations in average income between areas can be considered to be minimum estimates. Figure 3 shows a scatterplot of the estimated percentage of poor households against estimated average earnings for the 8519 electoral wards of England. The regression line with a 95\% confidence interval is also shown. There seems to be good agreement between these two variables (Pearson's product moment correlation $-0 \cdot 73)$.

\section{Conclusion}

To obtain accurate estimates of deprivation from the UK census it is necessary to use a weighted index. Allowance must be made for the fact that different groups have different probabilities of suffering from deprivation and poverty.

Validation is a crucial step in establishing the likely accuracy and precision of any census based deprivation index. Validation criteria are available both internally to the 1991 census (for example standardised illness ratios (SIRs) and estimated income) and also externally (for example standardised mortality ratios (SMRs) and benefit statistics).

The method of estimating the number of poor households in an area suggested by Gordon and Forrest ${ }^{1}$ has been shown to yield valid and reasonably accurate results for the 8519 electoral wards of England.

I thank Virginia Knight and Keith Cole of the Census Dissemination Unit, Manchester Computing Centre, and Ed Thomas of the Department of Geography, Bristol University. Particular thanks to Helen Anderson, for typing and editing this paper. The programming and work involved in creating the this paper. The programming and work involved in creating the estimated mean weekly income was undertaken jointly with Peter Lee at CURS, Birmingham University. I also thank Alastair Beattie for providing the details of the Townsend deprivation index.

Data from The Breadline Britain in the 1990s Survey were used to create the weightings used in estimating the percentage of poor households. This survey was funded by London Weekend Television (LWT) with additional funding from the Joseph Rowntree Foundation and was carried out by Marketing and Opinion Research International (MORI). It was conceived and designed by Joanna Mack and Stewart Lansley for Domino Films, with the help of Brian Gosschalk of MORI. Research for the six television programmes was by Harold Frayman with additional research by David Gordon and John Hills. Christina additional research by David Gordon and John Hills. Christina to use.

The source of the Census data are the 1991 Local Base Statistics $(100 \%$ and $10 \%)$ which are Crown Copyright. (c) The Breadline Britain in the 1990s Survey is copyright of MORI and Domino Films.

The 1991 census local base statistics and small area statistics $(100 \%$ and $10 \%)$ are Crown Copyright.

1 Gordon D, Forrest R. People and places 2. Social and economic distinctions in England 1991. Bristol; SAUS and the Statistical Monitoring Unit, 1995;135.

2 Forrest R, Gordon D. People and places. A 1991 census atla of England. Bristol: SAUS and the Statistical Monitoring Unit, 1993

3 Townsend P, Phillimore P, Beattie A. Inequalities in health in the Northern Region: an interim report. Newcastle upon Tyne and Bristol: Northern Regional Health Authority and the University of Bristol, 1986.

4 Department of the Environment Index of local conditions: an analysis based on 1991 census data. London: DOE. 1994.

5 Townsend P, Gordon D. What is enough? New evidence on poverty in Greater London allowing the definition of a minimum benefit. Memorandum of evidence to the House of Commons Social Services Select Committee on Minimum of Commons Social Services Select Committee

6 Townsend P. Poverty in the United Kingdom. Harmondsworth, Middlesex and Berkeley: Allen Lane and Penguin Books; University of California Press, 1979.

7 Townsend P. The International analysis of poverty, Milton Keynes: Harvester Wheatsheaf, 1993.

8 Piachaud D. Problems in the definition and measurement of poverty. Fournal of Social Policy 1987;16(2):125-46. 
9 Atkinson AB. How should we measure poverty? Some conceptual issues. Discussion Paper No 82, ESRC Programme on Taxation, Incentives and Distribution of Income. London: London School of Economics; 1985.

10 Atkinson AB. On the measurement of poverty. Discussion Paper no 90, ESRC Programme on Taxation, Incentives and the Distribution of Income. London: London School of Economics, 1985.

11 Lewis GW, Ulph DT. Poverty, inequality and welfare. The Economic fournal, 1988;98:117-31.

12 Townsend P. Deprivation. Fournal of Social Policy 1987; 16(2):125-46.

13 Frayman H. Breadline Britain - 1990s: The findings of the television series, London: Domino Films and London Weektelevision series, London

14 Gosschalk B, Frayman H. The changing nature of deprivation in Britain - an inner cities perspective. Political and social issues in urban industrial societies - joint session with WAPOR; 1991.

15 Gordon D, Pantazis C eds. Breadline Britain in the 1990s. Report to the Joseph Rowntree Foundation. York: Joseph Rowtree Foundation, 1995;251.

16 Mack J, Lansley S. Poor Britain. London: Allen and Unwin, 1985.

17 Gordon D, Townsend P. Measuring the poverty line. Radical Statistics 1990;47:5-12.

18 Hallerod B, Bradshaw J, Holmes H. Adapting the consensual definition of poverty. In: Gordon D, Pantazis C eds. Breadline Britain in the 1990s, Report to the Joseph Rowntree Foundation. York: Joseph Rowntree Foundation 1995, 161-82.

19 Davies $H$, Joshi $H$, Clarke $L$. Is it cash the deprived are short of? $\mathcal{F} R$ Stat $\operatorname{Soc} A$. (in press).

20 Noble $M$, Cheung SY, Smith G and Smith T. Using census data to predict income support dependency. Policy and Politics (in press)

21 Callaghan T, Nolan B, Whelan CT. Resources, deprivation and the measurement of poverty. Fournal of Social Policy. 1993;22(12):141-72.

22 Department of Social Security. Households below average income: a statistical analysis 1979-1991/92. London: HMSO, 1994;178.
23 Goodman A, Webb S. Low income statistics: low income families 1989-1992. Social Security Committee. House of Commons Official Report (Hansard) 1995;254:xxxii.

24 Townend P, Davidson N. Inequalities in health: the Black report. 2nd ed. Harmondsworth: Penguin Books, 1988.

25 OPCS. The Autumn 1987 census wording test: variation of long-term illness between areas. Consultation paper. London: OPCS, 1988

26 Charlton J, Wallace $M$, White I. Long-term illness: results from the 1991 census. Population Trends. 1994;75:18-25. 27 Banks J, Dilnot A, Low $\mathrm{H}$. The distribution of wealth in the $U K$. London: IFS. Commentary no 45; 1994.

\section{Open discussion}

JOSHI - This methodology appears to me to presuppose that there is a unidimensional "thing" underlying all these indicators - that they are all being used as indicators of one type of deprivation. Might there not be various different ways in which people might be deprived?

GORDON - Yes, deprivation is multivariate, almost by definition. We define poverty in terms of multiple deprivation. When we do this analysis we divide the groups into "poor" or "not poor" using the multivariate technique of discriminant analysis: we look at the different aspects of deprivation in relation to income, housing deprivation, deprivation of work, clothing deprivation, etc. But we do assume that there is such a thing as "poverty" and "not poverty". JOSHI - Or maybe there is cash poverty and time poverty.

GORDON - Certainly, these indices do not measure time poverty. 